УДК 635.0.813

\title{
ХИМИЧЕСКИЙ СОСТАВ ВОДНО-ЭТАНОЛЬНОГО ЭКСТРАКТА ДРЕВЕСНОЙ ЗЕЛЕНИ JUNIPERUS SIBIRICA BURGSD
}

\author{
() Е.В. Матвеенко ${ }^{I *}$, Н.А. Величко ${ }^{2}$, Г.С. Калачева \\ ${ }^{1}$ Сибирский государственный технологический университет, ул. Мира, 82, \\ Красноярск, 660049 (Россия), e-mail: vollker@mail.ru \\ ${ }^{2}$ Красноярский государственный аграрный университет, ул. Мира, 90, \\ Красноярск, 660049 (Россия) \\ ${ }^{3}$ Институт биофризики СО РАН, ул. Академгородок, 50, Красноярск, 660036 \\ (Россия)
}

Исходя из перспективности использования продуктов и полупродуктов из растительного сырья, актуальным является изучение их химического состава. Проводится анализ водно-этанольного экстракта, полученного из древесной зелени Juniperus sibirica B. Представлены используемые для проведения эксперимента методики. Исследован состав экстрагируемых из растительного сырья веществ, установлено общее количество белка, углеводов и липидов. Идентифицирован индивидуальный состав жирных кислот, минеральных и биологически активных веществ, содержащихся в 45\%-ном водно-этанольном экстракте древесной зелени Juniperus sibirica B. Из биологически активных веществ в экстракт перешли витамины различных групп, флавоноиды, хлорофиллы А и В. Среди жирных кислот обнаружены предельные и непредельные. Минеральный состав представлен калием, магнием, кальцием, фосфором, серой, железом и другими микроэлементами.

Ключевые слова: экстракт, химический состав, липиды, минеральные вещества, биологически активные вещества, Juniperus sibirica $B$.

\section{Введение}

Можжевельник сибирский (Juniperus sibirica B.) - многолетний хвойный двудомный кустарник, высотой до 1,5 м, с серо-бурой корой и остро-жесткими шиловидными, серповидно-изогнутыми листьями. Около 10 лет как вариация можжевельника обыкновенного, имеющего форму приземистого кустарника с распластанными по почве ветвями, выделен в самостоятельный сибирский вид - можжевельник сибирский [1]. Многочисленные упоминания в литературных источниках [2-3] о его разнообразном использовании в народной медицине стали предпосылкой к его изучению. Одним из компонентов, который может широко использоваться в композиции лечебных средств и натуральных полупродуктов для парфюмернокосметических, фармацевтических производств, является экстракт. В состав экстрагируемых из растительного сырья веществ входит большое число соединений, таких как белки, углеводы, витамины, органические кислоты и другие [4-5].

Целью исследования было изучение химического состава водно-этанольного экстракта древесной зелени можжевельника сибирского.

\section{Объект и методы исследования.}

Матвеенко Егор Владимирович - аспирант,

e-mail: vollker@mail.ru

Величко Надежда Александровна - доктор технических

наук, профессор

Калачева Галина Сергеевна - доктор биологических наук, заведующая аналитической лабораторией
Исходным сырьем была свежая древесная зелень Juniperus sibirica B., произрастающего на территории Партизанского района Красноярского края. Заготовка исследуемого материала проводилась в сентябре 2014 г. Образцы были собраны с 10-20 кустарников, усреднялись методом квартования.

\footnotetext{
* Автор, с которым следует вести переписку.
} 
Экстракцию древесной зелени Juniperus sibirica B. проводили раствором этилового спирта, при температуре кипения экстрагента и атмосферном давлении 736-738 мм рт.ст., в течение 150 мин. Концентрация этилового спирта $45 \%$ и гидромодуль $1: 40$ выбран на основании предварительно проведенных экспериментов [6-7]. Определение содержания общего азота проводили по Къельдалю [8]. Содержание биологически активных веществ в экстрактах определялось по методикам, принятым в химии и биохимии растений [8-10]. Минеральный состав водно-спиртового экстракта определяли по методикам, описанным в природоохранных нормативных документах [11-13].

Липиды экстрагировали из жидких проб гексаном трижды. К объединенным экстрактам добавляли дистиллированную воду и после разделения фаз собирали верхний гексановый слой, водную фазу обрабатывали гексаном, гексановые фракции объединяли, обезвоживали пропусканием растворителя через безводный сернокислый натрий, собирали во взвешенную колбу. Растворитель отгоняли на роторном испарителе, липиды досушивали в эксикаторе, их количество определяли взвешиванием. Метанолиз жирных кислот проводили в смеси метанола и серной кислоты (50:1 по объему) при температуре $90{ }^{\circ} \mathrm{C}$ в течение двух часов. По окончании метанолиза добавляли двойной объем воды и метиловые эфиры жирных кислот трижды экстрагировали из реакционной смеси гексаном. Гексановый экстракт промывали дистиллированной водой до нейтральной реакции и осушали пропусканием через слой безводного $\mathrm{Na}_{2} \mathrm{SO}_{4}$. Затем гексан отгоняли на роторном испарителе. Метиловые эфиры жирных кислот анализировали на газо-жидкостном хроматографе с масс-спектрометрическим детектором 6890N/5975 (Agilent, США). Условия анализа: газноситель - гелий, скорость - 1,2 мл/мин; температура ввода пробы $-230^{\circ} \mathrm{C}$; начальная температура хроматографирования $-60{ }^{\circ} \mathrm{C}$, подъем температуры до $190{ }^{\circ} \mathrm{C}$ со скоростью $3{ }^{\circ} \mathrm{C}$ в минуту, 5 мин изотермальный режим, затем подъем температуры до $220^{\circ} \mathrm{C}$ со скоростью $10^{\circ} \mathrm{C}$ в минуту и 20 мин изотермальный режим; температура детектора $-220^{\circ} \mathrm{C}$; колонка капиллярная HP-FFAP, длина 30 м, диаметр - 0,32 мм; режим электронного удара при $70 \mathrm{eV}$, режим сканирования фрагментов - от 45 до $580 \mathrm{~m} / \mathrm{z}$ при 0,5 c/скан. Идентификацию жирных кислот проводили по масс-спектрам и сравнением их времен удерживания с таковыми имеющихся стандартов. В качестве стандартов использовали насыщенные, разветвленные и моноеновые кислоты с длиной цепи от 10 до 24, а также линолевую, $\alpha$-линоленовую, $\gamma$-линоленовую, арахидоновую, эйкозапентаеновую и докозагексаеновую кислоты («Serva» Германия и «Sigma» CША). Расчет относительного содержания жирных кислот осуществляли методом внутренней нормализации [14-15].

\section{Обсуждение результатов}

Содержание общего белка, углеводов и липидов в $45 \%$-ном водно-спритовом экстракте древесной зелени можжевельника сибирского приведено в таблице 1. Полученные результаты показывают, что в водно-этанольном экстракте древесной зелени можжевельника сибирского присутствует значительное количество липидов, углеводов.

Ценными компонентами в экстракте являются биологически активные вещества, выход некоторых из них из древесной зелени можжевельника сибирского приведен в таблице 2.

Как следует из результатов, приведенных в таблице 2, в 45\%-ном водно-спиртовом экстракте древесной зелени можжевельника сибирского присутствуют витамины различных групп, флавоноиды, хлорофиллы А и В.

Индивидуальный состав жирных кислот 45\%-ного водно-спиртового экстракта древесной зелени можжевельника сибирского представлен в таблице 3. Состав кислот, метилирующихся метанолом, разнообразен. Среди них обнаружены предельные и непредельные жирные кислоты. Установлено высокое содержание $\alpha$-линоленовой и пальмитиновой кислот $(26,88-23,29 \%$ в расчете от суммы кислоты) а также значительное количество линолевой $(14,33 \%)$. Линолевая кислота и $\alpha$-линоленовая кислоты являются необходимыми для нормальной жизнедеятельности человека и животных. Из жирных кислот, обладающих известными лекарственными или бактерицидными свойствами, можно выделить: 4-деценовую, лауриновую и миристиновую. Идентифицированы смоляные кислоты - палюстровая, неоабиетиновая.

Установлено содержание минеральных веществ в 45\%-ном водно-спиртовом экстракте древесной зелени можжевельника сибирского (табл. 4). Обнаружено значительное содержание таких элементов, как калий, магний, кальций, фосфор, сера, железо и других микроэлементов. 
Таблица 1. Химический состав водно-спиртового экстракта древесной зелени можжевельника сибирского

\begin{tabular}{l|c}
\hline \multicolumn{1}{c|}{ Показатели } & Содержание \\
\hline Общие углеводы (г/л) & 1,7 \\
Белок (г/л) & 0,875 \\
Липиды (г/л) & 2,2 \\
\hline
\end{tabular}

Таблица 2. Выход биологически активных веществ из древесной зелени Juniperus sibirica $B$.

\begin{tabular}{l|c}
\hline \multicolumn{1}{c|}{ Компоненты } & Выход \\
\hline Витамин С, мг\% & $986,19 \pm 2$ \\
Витамин В, мг\% & $1,43 \pm 0,2$ \\
Витамин Р, мг\% & $24,12 \pm 2$ \\
Флавоноиды, мг\% & $335,14 \pm 2$ \\
Хлорофилл А+В, мг\% & $3,92 \pm 0,01$ \\
Каротин, мг\% & $0,19 \pm 0,01$ \\
Танниды, \% от а.с.м & $6,40 \pm 0,2$ \\
\hline
\end{tabular}

Таблица 3. Состав жирных кислот водно-спиртового экстракта древесной зелени можжевельника сибирского

\begin{tabular}{|c|c|c|c|}
\hline Жирные кислоты & $\begin{array}{c}\text { Содержание (\% от суммы } \\
\text { жирных кислот) }\end{array}$ & Жирные кислоты & $\begin{array}{c}\text { Содержание (\% от суммы } \\
\text { жирных кислот) }\end{array}$ \\
\hline 10:0 (декановая) & 0,16 & 18:0 (стеариновая) & 2,98 \\
\hline 10:1 (4-деценовая) & 0,28 & 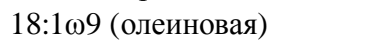 & 7,00 \\
\hline 12:0 (лауриновая) & 2,69 & 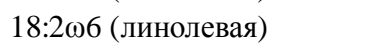 & 14,33 \\
\hline 14:0 (миристиновая) & 1,72 & 18:3ఱ3 ( $\alpha$-линоленовая) & 26,88 \\
\hline 15:0 (пентадекановая) & 0,58 & 20:0 (эйкозановая) & 1,71 \\
\hline 16:0 (пальмитиновая) & 23,29 & (неоабиетиновая) & 3,50 \\
\hline 16:1ఱ7 (гексадеценовая) & 0,34 & 22:0 (додекановая) & 2,83 \\
\hline 17:0 (маргариновая) & 0,77 & Palustric acid (палюстровая) & 1,79 \\
\hline 16:3ఱ3 (гексадекатриеновая) & 0,96 & 24:0 (тетрадекановая) & 8,20 \\
\hline
\end{tabular}

Таблица 4. Минеральный состав водно-спиртового экстракта древесной зелени можжевельника сибирского

\begin{tabular}{|c|c|c|c|}
\hline Показатели & Содержание, мг/л & Показатели & Содержание, мг/л \\
\hline $\mathrm{Al}$ - алюминий & 1,6128 & Mg - магний & 74,844 \\
\hline As - мышьяк & 0,07 & Mn - марганец & 1,8032 \\
\hline B - бор & 0,0952 & Мо - молибден & 0,0504 \\
\hline $\mathrm{Ba}$ - барий & 0,1176 & $\mathrm{Na}$ - натрий & $<0,02$ \\
\hline Вi - висмут & $<0,00317$ & $\mathrm{Ni}$ - никель & 0,518 \\
\hline $\mathrm{Ca}$ - кальций & 44,663 & P - общий фосфор & 33,267 \\
\hline $\mathrm{Cd}$ - кадмий & 0,0028 & $\mathrm{~Pb}-$ свинец & 0,1484 \\
\hline Со - кобальт & 0,0168 & $\mathrm{~S}$ - общая сера & 23,831 \\
\hline $\mathrm{Cr}-$ хром & 0,0308 & $\mathrm{Se}$ - селен & 0,2128 \\
\hline $\mathrm{Cu}-$ медь & 0,112 & $\mathrm{Sr}$ - стронций & 0,5096 \\
\hline $\mathrm{Fe}$ - железо & 3,7856 & V - ванадий & 0,0084 \\
\hline In - индий & 0,0868 & $\mathrm{Zn}$ - цинк & 0,2856 \\
\hline K - калий & 404,94 & & \\
\hline
\end{tabular}

\section{Вывод}

В работе представлены результаты по определению химического состава 45\%-ного водно-спиртового экстракта можжевельника сибирского. Установлен индивидуальный состав жирных кислот, минеральных и некоторых биологически активных веществ. В связи с наличием в 45\%-ном водно-спиртовом экстракте можжевельника сибирского ценных соединений его можно рекомендовать для получения фармацевтических и косметологических препаратов.

\section{Список литературы}

1. Коропачинский И.Ю. Древесные растения Сибири. Новосибирск, 1983. 383 с.

2. Гринкевич Н.И., Баландина И.А. Лекарственные растения. М., 1991. 398 с.

3. Минаева В.Г. Лекарственные растения Сибири. Новосибирск, 1991. 431 с.

4. Настойки, экстракты, эликсиры и их стандартизация / под ред. В.Л. Багирова, В.А. Северцев. СПб., 2001. $223 \mathrm{c.}$

5. Левин Э.Д., Репях С.М. Переработка древесной зелени. М., 1984. 120 с. 
6. Матвеенко Е.В., Аёшина Е.Н. Исследования экстрактивных веществ Juniperus sibirica B. // Молодые ученые в решении актуальных проблем науки: Всероссийская научно-практическая конференция (с международным участием): сборник статей студентов, аспирантов и молодых ученых. Красноярск, 2012. Т. 1. С. 276-277.

7. Матвеенко Е.В., Аёшина Е.Н., Величко Н.А. Состав экстрактов древесной зелени Juniperus sibirica Burgsd // Химия растительного сырья. 2013. №4. С. 175-177.

8. У Ушанова В.М., Лебедева О.И., Девятловская А.М. Основы научных исследований. Красноярск, 2004. 335 с.

9. ГОСТ 24027.2-80. Сырье лекарственное растительное. М., 1980. С. 284-294.

10. Левин Э.Д., Миронов П.В. Современные физико-химические методы исследования: методические указания к проведению лабораторных работ. Красноярск, 1988. 28 с.

11. ПНД Ф 16.2.2:2.3.71-2011. Методика измерений массовых долей металлов в осадках сточных вод, донных отложениях, образцах растительного происхождения спектральными методами. М., 2011.

12. ПНД Ф 14.1:2.141-98. МВИ жиров в природных и сточных водах. М., 2009.

13. ПНД Ф 14.1:2:4.143-98. МВИ алюминия, бария, бора, железа, калия, кальция, кобальта, магния, марганца, меди, натрия, никеля, стронция, титана, хрома и цинка в питьевых, природных, сточных водах. М., 2011.

14. Калачева Г.С., Жила Н.О., Волова Т.Г., Гладышев М.И. Влияние температуры на состав липидов Botryococcus // Микробиология. 2002. Т. 71. №3. С. 336-344.

15. Ермаков А.И., Арасимович В.В., Смирнова-Иконникова М.И., Ярош Н.П., Луковникова Г.А. Методы биохимического исследования растений. Л., 1972. 306 с.

Поступило в редакиию 20 февраля 2015 г.

После переработки 27 февраля 2015 г. 
Matveenko E..$^{*}$, Velichko $N^{2}$, Kalacheva $G^{3}$ CHEMICAL COMPOSITION OF WATER-ETHANOL EXTRACT WOOD GREENS JUNIPERUS SIBIRICA BURGSD

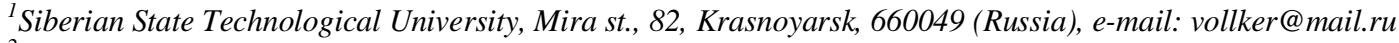

${ }^{2}$ Krasnoyarsk State Agricultural University, Mira st., 90, Krasnoyarsk, 660049 (Russia)

${ }^{3}$ Institute of Biophysics of the Russian Academy of Sciences, ul. Akademgorodok, 50, Krasnoyarsk, 660036 (Russia)

Based on the perspectives of products from vegetable raw materials, relevant is the study of their chemical composition. The article analyzes the water-ethanol extract derived from wood greens Juniperus sibirica B. Presented used for the experiment methodology. The composition extracted from vegetable raw materials, the total number of installed fiber, carbohydrates and lipids. Identified individual fatty acid composition, minerals and bioactive substances contained in a $45 \%$ aqueous-ethanolic extract of green wood Juniperus sibirica B. Of the biologically active substances in the extract of the various groups crossed vitamins, flavonoids, chlorophylls and B. Among the fatty acids found marginal and unsaturated. The mineral composition is presented in potassium, magnesium, calcium, phosphorus, sulfur, iron and other micronutrients.

Keywords: extract, chemical composition, biologically active substances, Juniperus sibirica $B$.

\section{References}

1. Koropachinskij I.Ju. Drevesnye rastenija Sibiri. [Woody plants of Siberia]. Novosibirsk, 1983, 383 p. (in Russ.).

2. Grinkevich N.I., Balandina I.A. Lekarstvennye rastenija. [Medicinal Plants]. Moscow, 1991, 398 p. (in Russ.).

3. Minaeva V.G. Lekarstvennye rastenija Sibiri. [Medicinal Plants of Siberia]. Novosibirsk, 1991, 431 p. (in Russ.).

4. Nastojki, jekstrakty, jeliksiry i ih standartizacija. [Tinctures, extracts, elixirs and standardization], ed. V.L. Bagirova, V.A. Severcev, Saint Petersburg, 2001, 223 p. (in Russ.).

5. Levin Je.D., Repjah S.M. Pererabotka drevesnoj zeleni. [Recycling wood greens]. Moscow, 1984, 120 p. (in Russ.).

6. Matveenko E.V., Ajoshina E.N. Molodye uchenye v reshenii aktual'nyh problem nauki: Vserossijskaja nauchnoprakticheskaja konferencija (s mezhdunarodnym uchastiem). Sbornik statej studentov, aspirantov i molodyh uchenyh. [Young scientists in solving actual problems of science: All-Russian Scientific Conference (with international participation). Collection of articles of students and young scientists]. Krasnojarsk, 2012, vol. 1, pp. 276-277. (in Russ.).

7. Matveenko E.V., Ajoshina E.N., Velichko N.A. Himija rastitel'nogo syr'ja, 2013, no. 4, pp. 175-177. (in Russ.).

8. Ushanova V.M., Lebedeva O.I., Devjatlovskaja A.M. Osnovy nauchnyh issledovanij. [Basic research]. Krasnojarsk, 2004, 335 p. (in Russ.).

9. GOST 24027.2-80. Syr'e lekarstvennoe rastitel'noe. [State Standard 24027.2-80. Raw medicinal plant]. Moscow, 1980, pp. 284-294. (in Russ.).

10. Levin Je.D., Mironov P.V. Sovremennye fiziko-himicheskie metody issledovanija: metodicheskie ukazanija $k$ provedeniju laboratornyh rabot. [Modern physico-chemical methods of research: guidelines for laboratory work]. Krasnojarsk, 1988, 28 p. (in Russ.).

11. PND F 16.2.2:2.3.71-2011. Metodika izmerenij massovyh dolej metallov v osadkah stochnyh vod, donnyh otlozhenijah, obrazcah rastitel'nogo proishozhdenija spektral'nymi metodami. [Federal environmental regulations 16.2.2:2.3.71-2011. Methods of measuring the mass fraction of metals in sewage sludge, sediment, samples of plant origin spectral methods]. Moscow, 2011. (in Russ.).

12. PND F 14.1:2.141-98. MVI zhirov v prirodnyh $i$ stochnyh vodah. [Federal environmental regulations 14.1:2.141-98. Microwave fat in natural waters and waste]. Moscow, 2009. (in Russ.).

13. PND F 14.1:2:4.143-98. MVI aljuminija, barija, bora, zheleza, kalija, kal'cija, kobal'ta, magnija, marganca, me-di, natrija, nikelja, stroncija, titana, hroma i cinka v pit'evyh, prirodnyh, stochnyh vodah. [Federal environmental regulations 14.1:2:4.143-98. Microwave aluminum, barium, boron, iron, potassium, calcium, cobalt, magnesium, manganese, copper, sodium, nickel, strontium, titanium, chromium and zinc in the drinking water, natural and waste waters]. Moscow, 2011. (in Russ.).

14. Kalacheva G.S., Zhila N.O., Volova T.G., Gladyshev M.I. Mikrobiologija, 2002, vol. 71, no. 3, pp. 336-344. (in Russ.).

15. Ermakov A.I., Arasimovich V.V., Smirnova-Ikonnikova M.I., Jarosh N.P., Lukovnikova G.A. Metody biohimicheskogo issledovanija rastenij. [Methods of biochemical research plant]. Leningrad, 1972, 306 p. (in Russ.).

Received February 20, 2015

Revised February 27, 2015

\footnotetext{
* Corresponding author.
} 
